\title{
Responsible Attention to Conflicts of Interest Enhances the Credibility of Published Scholarship
}

\author{
Mark B. Mycyk ${ }^{1}$
}

Received: 19 November 2018 / Accepted: 20 November 2018 / Published online: 26 November 2018

(C) American College of Medical Toxicology 2018

As Journal of Medical Toxicology (JMT) launches its 15th year of publishing, the fresh start of the new year allows us to remind readers of our commitment to transparency and fairness in all forms of scholarly dissemination. We have previously written about the importance of ethical conduct in publishing to maintain public trust in journals [1]. Recent high-profile news about inappropriate financial ties between prominent researchers and drug industry prompt us to dedicate some space here to conflicts of interest (COI) [2].

The recent spotlight on COI and the heated debates about what should be defined as a COI are not new [3-5]. The International Committee of Medical Journal Editors (ICMJE) has taken the most visible lead on clarifying the roles and obligations of authors and journals with regard to conflicts [6]. JMT is proud to be listed among other prominent journals that have pledged to follow ICMJE's recommendations for the "conduct, reporting, editing and publication of scholarly work in medical journals" [7]. The ICMJE website includes several excellent resources for scholars, and we fully endorse the principles in their COI link: "Public trust in the scientific process and the credibility of published articles depend in part on how transparently conflicts of interest are handled during the planning, implementation, writing, peer review, editing, and publication of scientific work. A conflict of interest exists when professional judgment concerning a primary interest (such as patients' welfare or the validity of research) may be influenced by a secondary interest (such as financial gain)." The ICMJE website provides guidance on determining whether a conflict exists, and their site even includes a downloadable form that may be used when submitting to any journal.

To date, most COI policies at medical journals have focused on disclosure of financial relationships because those

Mark B. Mycyk

mmycyk@cookcountyhhs.org

1 Department of Emergency Medicine, Cook County Health, 1950 West Polk Street, Chicago, IL 60612, USA are the easiest to identify and track. For those interested in the historic origins of journal COI disclosure requirements, the persuasive 1984 editorial in the New England Journal of Medicine (NEJM) by editor-in-chief Arnold S. Relman is a good place to start [8]. In that piece, he boldly asked, "What policies should govern the review and publication of research work when conflicts of interest may exist?" and then proceeded to explain why the $N E J M$ chose to adopt a COI disclosure policy for the first time that year, and soon other journals followed their lead.

At JMT, we think it is just as important to be aware that COI can occur for non-financial reasons [9]. In that same 1984 editorial, it was prescient of Relman to mention, "We recognize that in some sense, authors may be affected by conflicts of interest even when no commercial considerations are involved. Competitive pressures and concerns about research grants, peer recognition, or academic advancement may adversely influence behavior" [8]. Yes, the italicized word "some" is Relman's in his original editorial. How a journal could monitor non-financial conflicts back then was not clear. ICMJE currently recognizes this as an important issue ("conflicts can occur for other reasons, such as personal relationships or rivalries, academic competition, and intellectual beliefs"), but little guidance for monitoring or enforcement are offered [6]. JMT is also a member of the Committee on Publication Ethics (COPE), and almost half of the dilemmas about COI posed to the COPE forum by editors for advice deal with non-financial conflicts [10].

It is important for readers to understand that a disclosed conflict does not mean that any harm was done because of secondary gain: it simply means there is a risk of harm that is being disclosed [11]. This is consistent with the Institute of Medicine's 2009 report where a conflict of interest is defined as "a set of circumstances that creates a risk that professional judgment or actions regarding a primary interest will be unduly influenced by a secondary interest" [12]. And a disclosed conflict does not necessarily make a research study bad or dishonest. Too often during journal clubs, when the presenter 
or another discussant mentions the financial conflicts listed at the end of a paper, eyes roll and the work is too quickly dismissed as tainted or unreliable. That should not be our reflexive assumption. We need to be partners with industry, funders, and other stakeholders to ensure the process is transparent and honest. We need to concede that some studies could not be done without extramural funding from either industry or government. The intent of journal disclosure policies is "to guide, not prohibit relationships with commercial entities that may advance research leading to improvements in patient care" [13]. Disclosure is simply the means for preserving the "trustworthiness" of the scientific enterprise [14].

The big limitation with COI disclosures is the lack of a formal mechanism for enforcing compliance. It is up to the authors to submit a COI disclosure with the manuscript during initial review. At $J M T$, like at other journals, we explicitly instruct authors to submit their COI forms and hope they follow those instructions. In some cases, the failure to disclose $\mathrm{COI}$ adequately is an honest mistake, especially with novice scholars, because there are no required courses on disclosure [13]. It is assumed investigators just know how to do so, because they learned from the example of their mentors and the questions in the COI forms mostly require a yes or no response. Disclosure of conflicts should be common sense. However, anytime an experienced and renowned researcher is discovered to neglect proper disclosure, it is not surprising when everyone takes notice and trust in the whole scientific process is eroded [2]. The public relies on journals to be a source of unbiased and ethically done scholarship [1,5]. Many assume journals should monitor or enforce COI policies better, but journals are not equipped to police their authors or $\mathrm{COI}$ forms. The responsibility for disclosing COI belongs to every listed author.

The world is small, and the world of toxicology scholars is even smaller, so conflicts are inevitable. As Jeffrey Flier wrote in a 2017 JAMA issue exclusively devoted to conflicts of interest: "COI are universal and inherent to the human experience and could never possibly be eliminated" [3]. At JMT, we take conflicts of interest seriously, but that should not discourage authors from submitting their work to JMT. Authors need to be honest and transparent and acknowledge them so we can evaluate their work as fairly as possible. Authors should also know we hold our peer reviewers to the same high standard - if an invited reviewer has a conflict that has the potential to complicate the review process, that reviewer should contact the decision editor directly or ask to be recused from the assignment. And finally, we hold each of our editors to the same high bar-any commitments, both financial and non-financial, that would in any way complicate how we make a decision to accept or reject a work need to be recognized and identified to the editor-in-chief (EIC) or one of the other senior editors if the conflict involves the EIC.
Yes, we admit there are annoyances with the current system that interfere with submitting a COI form easily. Some of the excuses heard at $J M T$ and other journals why COI forms are sometimes incomplete or missing with the initial submission include the following: "The COI questions are too confusing..." "The COI forms are too darn redundant..." "The COI forms are frustratingly difficult to download..." Almost every published author has shared the experience of trying to download the right form but ends up with the "Please wait..." error message in the PDF because their operating system is incompatible with the electronic download. None of those reasons is acceptable for bypassing this important step when submitting a manuscript for eventual publication. All stakeholders in published scholarship, including investigators, clinicians, policy makers, and the patients we treat, need their confidence reassured in the scientific process, and proper attention to COI forms is a critical step. If any questions completing the $\mathrm{COI}$ form, please reach out to us. If any problems downloading the form, try the one at ICMJE website or contact us. Follow common sense. When in doubt, it is best to disclose [15]. If unsure what needs disclosure, reach out to us for guidance. We agree with other journal editors who have written that increasing awareness on how COI may influence scholarship is an important priority to restore credibility in the scientific enterprise [5, 14].

The ultimate value and lasting impact of a published work, whether it is a rigorously done study or an expert editorial, is determined by the readers themselves. That assumes the readers are making an informed judgment; if they are not adequately informed of conflicts, then their judgment is arguably not an informed one. We owe it to our readers to offer them all relevant information to do what they will with the work they read. We hope everything that is published in some way adds new knowledge or changes existing knowledge in some meaningful way. Trust in this imperfect system requires our best effort to preserve it, because that is the essential purpose of policies about conflict of interest [15].

In conclusion, we would like to thank the authors who continue to choose $J M T$ for disseminating their scholarship, the careful reviewers who take time out of their busy schedules to provide us with detailed critical feedback, and the editors who work behind the scenes to ensure the best possible work is published. We recognize no one has ever conducted a perfect study or published a perfect paper - we do the best we can with the cards we are dealt. We are proud of our work at this journal and look forward to 15 more years.

\section{Compliance with Ethical Standards}

Conflict of Interest Mark B. Mycyk, MD, is the editor-in-chief of Journal of Medical Toxicology (JMT).

Sources of Funding None. 


\section{References}

1. Mycyk MB. Maintaining the public trust in journals with ethical publishing. J Med Toxicol. 2017;13(4):275-7.

2. Ornstein C, Thomas K. Top cancer researcher fails to disclose corporate financial ties in major research journals. New York Times. https://www.nytimes.com/2018/09/08/health/jose-baselga-cancermemorial-sloan-kettering.html. Published September 8, 2018. Accessed 18 Sept 2018.

3. Flier J. Conflict of interest among medical school faculty achieving a coherent and objective approach. JAMA. 2017;317(17):1731-2.

4. Horton R. Offline: The BMJ vs NEJM - lessons for us all. Lancet. 2015;385:2238.

5. Steinbrook R, Kassirer JP, Angell M. Justifying conflicts of interest in medical journals: a very bad idea. BMJ. 2015;350:h2942.

6. ICMJE. http://www.icmje.org. Accessed 1 Nov 2018.

7. ICMJE. http://www.icmje.org/journals-following-the-icmjerecommendations. Accessed 1 Nov 2018.
8. Relman AS. Dealing with conflicts of interest. N Engl J Med. 1984;310(18):1182-3.

9. Edwards MA, Roy S. Academic research in the 21st Century: maintaining scientific integrity in a climate of perverse incentives and hypercompetition. Environ Eng Sci. 2017;34(1):51-61.

10. Shawwa K, Kallas R, Koujanian S, et al. Requirements of clinical journals for authors' disclosure of financial and non-financial conflicts of interest: a cross sectional study. PLoS ONE. 2016;11(3): e0152301.

11. McCoy MS, Emanuel EJ. Why there are no "potential" conflicts of interest. JAMA. 2017;317(17):1721-2.

12. Lo B, Field MJ, editors. Conflict of interest in medical research, education, and practice. National Academies Press; 2009.

13. Wayne DB. Teaching medical students about conflicts of interest. JAMA. 2017;317(17):1733-4.

14. Gjersvik P. Conflicts of interest in medical publishing: it's all about trustworthiness. Br J Dermatol. 2015;173:1255-7.

15. Fineberg HV. Conflict of interest: why does it matter? JAMA. 2017;317(17):1717-8. 